\title{
Formalização de serviços internos em grandes corporações: proposta de ontologia para construção colaborativa de Carta de Serviços
}

Maurício Telles Bígio

\author{
Mestre em Gestão do Conhecimento e da \\ Tecnologia da Informação. \\ Federal. \\ Funcionário de carreira da Caixa Econômica
}

Remis Balaniuk

Doutor em Ciência da Computação. Professor do Mestrado em Gestão do Conhecimento e Tecnologia da Informação

Ana Paula Bernardi da Silva

Doutora em Engenharia de Sistemas Eletrônicos e Automação. Professora do Mestrado em Gestão do Conhecimento e Tecnologia da Informação

Vitória Santiago da Silveira

Graduanda em Engenharia civil pela Universidade Católica de Brasília e e bolsista pela Fundação de Apoio a Pesquisa do Distrito Federal

http://dx.doi.org/10.1590/1981-5344/3261

As instituições que criam novos conhecimentos de forma sustentável e os disseminam por toda a organização possuem capacidade de inovar, melhorando seus processos e contornando crises. Os serviços internos quando não geridos adequadamente podem gerar gargalos que afetam o desempenho institucional como um todo. Esses reflexos podem ser sentidos tanto nas organizações privadas quanto públicas, mas nessas últimas acabam prejudicando a entrega dos serviços e políticas públicas ao cidadão. Assim, a presente pesquisa buscou contribuir com a melhoria da eficiência e da eficácia na administração pública, ao analisar a questão dos serviços internos sob uma ótica formal e estruturante baseada em ontologias e Cartas de Serviços. Utilizou-se 
como foco de pesquisa um grande banco público, representativo da administração indireta. Dentre os resultados houve satisfatória utilização da metodologia proposta, criação de uma ontologia para o contexto pretendido (OntoCSI), criação de uma aplicação wiki e avaliação desta interface junto às partes interessadas.

Palavras-chave: Ontologia. Arquitetura da Informação. Gestão do Conhecimento. MAIA.

\section{Formalization of internal services in large corporations: Ontology proposal for collaborative construction of Service Charter}

The institutions that create new knowledge in a sustainable manner and spread it throughout the organization have ability to innovate, improving its processes and bypassing crisis. Internal services when not properly managed may generate bottlenecks that affect institutional performance as a whole. These consequences can be felt both in private and public organizations, but in the last they end up harming the delivery of services and public policies to the citizen. Thus, the present study sought to contribute to the improvement of efficiency and effectiveness in public organizations by analyzing the issue of internal services from a formal and structuring perspective based on Ontologies and Service Charters. A large Public Bank, representative of the Brazilian indirect administration, was used as research focus. Among the results was a satisfactory use of the proposed methodology, creation of an ontology for the intended context (OntoCSI), creation of a wiki application and evaluation of this interface with stakeholders.

Keywords: Ontology. Information Architecture. Knowledge Management. MAIA.

Recebido em 13.08.2017 Aceito em 06.04.2018

\section{Introdução}

Existe grande quantidade e diversidade de processos de trabalho nas grandes organizações. Considerando um contexto de intensa atividade 
e de alta rotatividade entre seus quadros, o esforço requerido dos funcionários na busca por informação e conhecimento necessários para a execução de suas tarefas cotidianas pode acarretar atrasos, perda de produtividade, erros e redundâncias gerando prejuízo significativo para a organização. Por outro lado, as instituições que gerem adequadamente seu conhecimento de forma sustentável e os disseminam entre seus quadros e unidades tendem a lidar melhor com as oscilações na distribuição dos recursos humanos e na demanda a eles imposta e conseguem manter seus processos de trabalho funcionando de maneira eficiente.

A falta de informação tempestiva dentro dos processos de trabalho da organização tem ainda outras consequências indiretas, como a sobrecarga de trabalho aos funcionários mais experientes através de consultas, conversas, compartilhamento de experiência e outros (BASILI et al., 2001). No mesmo cenário, Gordon e Lowe (2002) afirmam que apenas a perda de conhecimento organizacional gerada pela rotatividade de pessoal (turnover) pode causar danos para as empresas norteamericanas na ordem de $\mathrm{R} \$ 300$ bilhões de reais/ano.

A perda de conhecimento organizacional pode ser definida como a evaporação, intencional ou não, do conhecimento que se acumula a partir da aprendizagem e de ações individuais e coletivas (PERROTT, 2007). Por outro lado, reter conhecimento significa preservar e aperfeiçoar as variações nos comportamentos adotados por uma organização e a subsequente dispersão através de toda estrutura da mesma (MADSEN; MOSAKOWSKI; ZAHEER, 2002). Daghfous, Belkhodja e Angell (2013) sugerem que para mitigar perdas, as organizações devem manter e difundir o conhecimento de forma arquitetônica, melhorar a coordenação estratégica entre as unidades e desenvolver capacidades existentes através de redes com o intuito de integrar o conhecimento nas rotinas organizacionais.

Neste sentido, surge a Gestão do conhecimento (GC), processo pelo qual são gerenciados ativos centrados no ser humano, de forma a preservar e promover o crescimento do conhecimento dos indivíduos, e compartilhá-lo com outros funcionários (BROOKING, 1999).

Nesse trabalho estamos particularmente interessados no tema dos serviços internos, definidos como sendo serviços nos quais o prestador e o beneficiário são ambos funcionários da mesma organização e que ocorrem no contexto de processos de trabalho internos. Esses serviços tendem a receber menos atenção dos gestores, talvez por causarem menos impacto junto ao consumidor final, mas podem representar uma parcela significativa de todo esforço requerido e realizado pela força de trabalho da organização. Quando mal geridos esses serviços frequentemente representam gargalos no funcionamento das organizações, tangibilizados por erros, atrasos e baixa qualidade/eficiência, entre outros, com reflexos significativos no produto/serviço final (CAMPI, 2012; KAPLAN; NORTON, 2001; SLACK; CHAMBERS; JOHNSTON, 2009). 
Montantes consideráveis de recursos são investidos em políticas, consultorias, tecnologias, equipamentos e métodos para gerir a informação e o conhecimento. No entanto, há dificuldades em implantar métodos com resultados significativos. Segundo Moresi, Ramos e Prado (2010), isto ocorre porque, entre outros fatores, a tecnologia é vista como ponto de partida para o compartilhamento de conhecimento, desconsiderando-se inúmeras vezes o fator humano.Percebe-se, então, uma necessidade maior que puramente obter novas e mais potentes tecnologias para apoiar os processos de trabalho. É preciso padronização, organização e gestão sobre o conhecimento que a instituição já possui, essencialmente, aquele presente nas pessoas (conhecimento tácito). A comunicação e a interação, virtual ou presencial, possuem importante papel no processo de integração da GC no planejamento estratégico.

Al-Alawi, Al-Marzooqi e Mohammed (2007) apontam a necessidade de mais pesquisas sobre GC focadas em instituições governamentais.Já o Ministério do Planejamento, Orçamento e Gestão (BRASIL, 2008) aponta como desafios à máquina pública brasileira elevar o padrão dos serviços prestados ao cidadão e estimular a participação popular. Esta última publicação se refere ao GESPUBLICA, programa criado em 2005 focado na qualidade e na desburocratização do serviço público.

Nesse artigo utilizamos o conceito de Carta de Serviço (CS), proposto pelo programa GESPUBLICA, adaptando-o para fundamentar o conceito de Carta de Serviços Internos (CSI). A CS consiste em um documento elaborado pelas organizações públicas visando informar 0 cidadão a respeito dos serviços prestados por elas, enquanto que a CSI adapta a mesma proposta para um compromisso assumido entre unidades de uma mesma organização com relação aos serviços prestados por cada uma. Em sua essência as CS tratam basicamente o mesmo problema de representação formal e consensual de conceitos, tratado também pelas ontologias. A escolha das ontologias como base formal para a definição da estrutura das CSI deveu-se a esse alinhamento.

As ontologias se caracterizam por representar formalmente 0 conhecimento com determinado nível de consenso. Elas podem contribuir com o tema dos serviços internos como forma de explicitação do conhecimento inerente a eles, para assim permitir a retenção e o compartilhamento desse conhecimento dentro da organização. De acordo com Andrade et al. (2011), entre os benefícios do uso de ontologias, destacam-se: redução de falhas nos processos e no apoio à tomada de decisão, preservação do capital intelectual, promoção do aprendizado organizacional e aumento das vantagens competitivas.

Hoehndorf et al. (2009) discursam sobre a lacuna entre o esforço necessário para a concepção de ontologias (criação de conhecimento e tempo) e a necessidade de manutenção da base de conhecimento (anotar novos dados e atualizar os modelos existentes). Como resposta, propõem uma wiki com núcleo ontológico para dar consistência e vazão ao conhecimento descrito por uma comunidade científica, a BOWiki. 
As wikis são páginas web com conteúdo criado e atualizado colaborativamente, com importância crescente no cenário laboral (MANDAJI, 2012). Batista (2014) categorizou-as como prática de GC relacionada à gestão de recursos humanos, por estarem mais próximas às relações humanas que à tecnologia em si, fator proposto por Moresi, Ramos e Prado (2010). Coutinho (2014) destaca que as informações advindas dos fóruns, bate-papos e wikis é difusa e difícil de organizar, fato que poderia ser mitigado com o uso de uma ontologia aplicada à captura das informações-alvo, como na BOWiki.

Almahamid e McAdams (2010) indicam que as práticas de compartilhamento de conhecimento influenciam a capacidade de adaptação, compromissos de aprendizagem e aumento da satisfação no trabalho dos funcionários. Pontos positivos para o uso das wikis em ambiente laboral. Quanto ao meio de representação final, foca-se nas wiki devido ao seu potencial de alcance dentro das instituições, à sua facilidade de uso e à aceitação das pessoas deste tipo de plataforma. Seu ambiente colaborativo contribui também com a avaliação e o aprimoramento contínuo da ontologia, permitindo sua evolução.

De acordo com o cenário apresentado, e considerando o conhecimento como um dos ativos mais valiosos para as instituições, o problema tratado neste artigo pode ser assim sumarizado: como reter e compartilhar o conhecimento acerca dos serviços internos de uma organização de forma eficiente, melhorando a qualidade dos processos e, consequentemente, melhorando a qualidade da relação com o cliente final considerando um ambiente com alta rotatividade de pessoal e diversidade de serviços.

O objetivo principal deste artigo é identificar e organizar os principais conceitos e relações no contexto dos serviços internos de uma grande organização prestadora de serviços, tomando como base um ente típico da administração pública indireta brasileira. Esse objetivo é atingido por meio da proposta de uma ontologia de domínio que, esperamos, possa ser útil na criação e manutenção de cartas de serviços internos.

Como objetivos secundários, o artigo busca: listar e definir os conceitos fundamentais no domínio estudado; identificar, a partir da lista anterior, termos em torno dos quais não há acordo consensual; apresentar um modelo conceitual da ontologia criada e listar os serviços que mais carecem de gestão do conhecimento na organização estudada. Além disso, o artigo descreve uma experiência realizada com o apoio de uma aplicação wiki visando avaliar e aprimorar a ontologia criada de forma colaborativa.

\section{Referencial teórico}

\subsection{Gestão do conhecimento (GC)}

A GC auxilia na mitigação da perda de conhecimento, pois, quanto maior a instituição, maior a possibilidade das pesadas rotinas operacionais 
e da rotatividade, entre outros fatores, produzirem este fenômeno prejudicial. Os objetivos finais da GC são eficiência, efetividade e qualidade (BATISTA, 2012).

Vale ressaltar que não existe consenso sobre o conceito de GC. Muitos termos são utilizados com significados divergentes e muitas definições se baseiam nos aspectos práticos de sua aplicação (SIQUEIRA, 2012). Contudo, como área emergente, é essencial que haja tal discussão para o amadurecimento do tema. Portanto, foi adotada a definição de GC dada por Batista (2012):

Gestão do Conhecimento é um método integrado de criar, compartilhar e aplicar o conhecimento para aumentar a eficiência, melhorar a qualidade e a efetividade social; e contribuir para a legalidade, impessoalidade, moralidade e publicidade na administração pública e para o desenvolvimento brasileiro. (BATISTA, 2012, p. 49).

Neste sentido, o citado autor elaborou o modelo denominado Ciclo KDCA (Figura 1), específico para a Gestão Pública, genérico com relação às instituições e simples na implementação. Ele está intimamente ligado às etapas comuns de planejamento e gestão, pois é uma variação do clássico ciclo PDCA (do inglês: plan, do, check, act ou planejar, fazer, conferir, corrigir) de Edwards Deming. O modelo é muito útil na medida em que incrementa os processos que já ocorrem naturalmente segundo as teorias da administração nas empresas e outros tipos de organizações e, portanto, é o modelo de GC adotado neste artigo.

Figura 1 - Ciclo KDCA

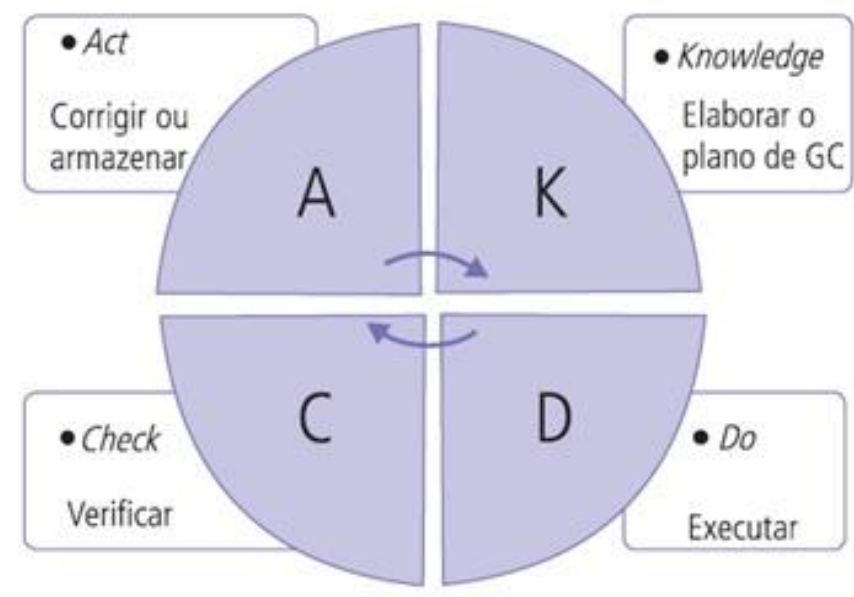

Fonte: BATISTA (2012).

Desta forma, a relação entre as unidades ou departamentos da organização, a efetividade operacional, as competências e as responsabilidades de cada uma, juntamente com a governança implantada e gestão de recursos humanos (entre outros), terão papel fundamental na GC. Para Kaplan e Norton (2001), a sinergia em uma 
organização surge desta interação entre as unidades de negócio e, por consequência, da qualidade das solicitações entre as mesmas unidades.

Eiriz, Simões e Gonçalves (2007) relacionam 14 obstáculos às iniciativas de GC. Entre os quais estão: falta de integração de iniciativas de gestão do conhecimento nas metas da organização; cultura organizacional não favorável, ausência de sistema claro de recompensas; canais de comunicação pouco eficientes; dificuldade das pessoas em traduzir o seu conhecimento; e falta de espaços formais ou informais para partilhar e gerar conhecimento.

Percebe-se, então, que a GC precisa estar integrada aos processos da instituição como um todo. Enquanto as pessoas a entendem como um processo a mais, uma nova atividade, ela se torna concorrente e menos importante que as atividades fim pré-existentes, tanto a nível operacional quanto estratégico (EIRIZ; SIMÕES; GONÇALVES, 2007).

\subsection{A carta de serviços (CS)}

O GESPUBLICA, programa criado em 23 de fevereiro de 2005, é a versão atual de programas brasileiros iniciados na década de 90 (fusão do Programa da Qualidade no Serviço Público e do Programa Nacional de Desburocratização) que tinham por objetivo incentivar a administração pública voltada ao cidadão, ou seja, gestão da qualidade dos serviços prestados e, simultaneamente, promover a participação do cidadão para igualmente promover a melhoria da qualidade dos atendimentos (BRASIL, 2008).

Em sua última reedição, em 2008, foi criada a figura da CS, documento elaborado pelas organizações públicas que visa informar aos cidadãos sobre os serviços prestados por elas, como acessar e obter esses serviços e quais os compromissos de atendimento estabelecidos. Seus princípios estão baseados nas premissas de foco no cidadão (orientar os processos de trabalho de forma a satisfazer suas necessidades) e indução do controle social, a disponibilização de meios para que o cidadão possa avaliar e fiscalizar os serviços prestados pelo Estado (BRASIL, 2008).

Os princípios de "comprometimento e participação" e "aprendizagem" referem-se à responsabilidade de todos os integrantes da organização com elaboração e prestação dos serviços, destacando-se o papel da Alta Administração no processo, e o incentivo à inovação e melhoria em cada atividade. "Transparência e informação" refere-se à forma como o Estado proverá ao cidadão formas de participar e criticar os processos. Todos os princípios norteiam os diretos civis no sentido da liberdade de expressão e de acesso aos serviços públicos fundamentais.

A administração pública federal é obrigada pela Lei 6.932, de 2009, a fornecer tais cartas ao cidadão e sua disponibilização tem por objetivo: melhorar a relação com os cidadãos; divulgar os serviços prestados pelas organizações públicas com os seus compromissos de atendimento, de forma que sejam amplamente conhecidos pela sociedade; fortalecer a confiança e a credibilidade da sociedade na administração pública quando 
esta percebe uma melhora contínua em sua eficiência e eficácia; e garantir o direito do cidadão para receber serviços em conformidade com as suas necessidades (BRASIL, 2009).

\subsection{Carta de Serviços Interna (CSI)}

Apesar de a GESPUBLICA ser enfática na questão de priorizar o serviço diretamente ao cidadão, a GC se aplica principalmente sobre os processos internos das instituições. Portanto propõe-se formalizar os serviços internos justamente sobre este domínio, pois as requisições entre as unidades e departamentos também são caracterizadas por relação de cliente e fornecedor e, frequentemente, representam "gargalos" nas organizações. Melhorar a eficiência destes serviços pode contribuir definitivamente para melhorar a qualidade do atendimento ao cidadão.

Gianesi e Corrêa (1996) definem os serviços internos como as atividades de apoio executadas pelas diversas subdivisões funcionais (unidades) das organizações, por exemplo: gerências, departamentos, agência e seções. Em geral, são regidos por normas internas que definem os papéis e responsabilidades das unidades. Porém, ocorre que as normas não acompanham tempestivamente 0 surgimento de novas responsabilidades ou alternância de papéis.

Da mesma forma, as normas não possuem a capacidade de representar todo o conhecimento sobre como realizar o papel ou citar todos os processos de responsabilidade das unidades. Neste contexto, se enquadrarão a ontologia sobre serviços internos e a plataforma wiki, para padronizar, racionalizar, dar alcance e "liquidez" ao conhecimento sobre tais serviços.

Adicionalmente, e como já citado, para a GC ser eficaz no contexto interno das organizações, faz-se necessário agregar a visão de como prestar o serviço (know-how) e quais são os procedimentos e detalhes internos para tal, uma vez que se pretende incrementar qualidade e agilidade destas obrigações. Portanto, a descrição dos procedimentos operacionais é essencial.

\subsection{Ontologias}

Siqueira (2012), em uma abordagem fenomenológica para a caracterização da área científica, definiu Arquitetura da Informação (AI) como a configuração dos estados dos Entes e de suas Relações, caracterizada pelo espaço-temporalidade das informações distinguidas. 0 autor descreve que qualquer $\mathrm{AI}$ é composta por quatro elementos fundamentais: forma, manifestação, contexto e significado.

Este autor apresenta ainda uma Teoria Geral da AI e uma estrutura de aplicação deste modelo, lista um conjunto de princípios tecnológicos que norteiam a prática da AI na construção de soluções e caracteriza uma fundamentação tecnológica para a disciplina. O trabalho pode ser considerado uma quebra de paradigma neste campo de estudo e da citada 
teoria emergiu um método denominado Construção de Arquitetura da Informação Aplicada (MAIA) (COSTA, 2009).

No contexto da AI, Sérgio, Da Silva e Gonçalves (2016) indicam que ontologias são instrumentos com alto potencial para organizar e representar informações de diferentes domínios e áreas de pesquisa. Elas fornecem mecanismos para representar o conhecimento destacando as relações semânticas entre eles, e não somente a sintática dos dados. Podem ainda ser utilizadas para melhorar a qualidade dos modelos conceituais e das linguagens de modelagem. Portanto, são adequadas para contexto em que formalizar o conhecimento torna-se necessário.

As ontologias, segundo Semprebom ${ }^{1}$ et al. (2007 apud STACHEIRA, 2014), são basicamente representações formais do conhecimento acerca de certos constructos. Explicitam o conhecimento sobre determinado domínio, descrevendo-o de forma não necessariamente hierárquica, estabelecendo as relações entre os conceitos envolvidos.

Almeida e Bax (2003) e Gomez-Perez et al. ${ }^{2}$ (2004 apud STACHEIRA, 2014), simplificam a classificação das ontologias sem alterar as definições e com base na abstração presente, da seguinte forma: Ontologias de Representação, Gerais, Genéricas (ou Centrais), de Domínio e de Aplicação. Para Guizzardi e Guizzardi (2008) existe ainda um nível acima das Ontologias de Representação, as Ontologias de Fundamentação (Foundation Ontologies). Os autores as caracterizaram como "sistemas de categorias filosoficamente bem fundamentados $e$ independentes de domínio que têm sido utilizados para melhorar a qualidade de linguagens de modelagem e modelos conceituais", são do maior grau de abstração.

\subsection{Construção de ontologias}

Beira (2015) propõe a utilização do MAIA para a construção de ontologias de domínio. A autora buscou identificar as práticas de criação de ontologias dentro dos paradigmas tecnológicos existentes e caracterizar as contribuições da AI para o seu desenvolvimento como ferramentas de GC, utilizando para isso ampla revisão de literatura. A autora identificou que o MAIA tem potencial para embasar ontologias de domínio, pois reúne elementos bem definidos em fenomenologia para formar sua abordagem teórica.

Costa (2009) define o MAIA como um método para a AI aplicado ao tratamento característico de informação organizacional, é composto de quatro momentos: Escutar, Pensar, Construir e Habitar. Todos se orientam para a construção do espaço de informação em uma abordagem fenomenológica, ou seja, segundo o ponto de vista de um sujeito determinado e se repetem ciclicamente. É considerado que a realidade não pode ser alcançada, apenas aproximada segundo este ponto de vista. A Tabela 1 destaca as principais características de cada momento.

\footnotetext{
${ }^{1}$ Disponível em: <www.das.ufsc.br/ gb/pg-ia/Protege07/ontologias.pdf>. Acessa em: 15 set. 2015.

2 GOMES-PEREZ, A. Tutorial on Ontological Engineering. Internacional Joint Conference on Artificial Intelligence - IJCAI, 1999
} 
Formalização de serviços internos em grandes corporações: Proposta de ontologia para construção colaborativa de Carta de Serviços
Maurício Telles Bígio; Remis Balaniuk; Ana Paula Bernardi da Silva; Vitória Santiago da Silveira

Tabela 1 - Descrição dos momentos do MAIA

\begin{tabular}{c|l|l}
\hline Momento & \multicolumn{1}{c|}{ Descrição } & \multicolumn{1}{c}{ Ações } \\
\hline \hline Escutar & $\begin{array}{l}\text { Momento inicial de delimitação do espaço de } \\
\text { informação, é composto pelo ato de ouvir e pelo ato de } \\
\text { interpretar, que revelam a intenção do sujeito }\end{array}$ & $\begin{array}{l}\text { - Fazer o registro das percepçóes } \\
\text { interesse }\end{array}$
\end{tabular}

\begin{tabular}{|c|c|c|}
\hline Pensar & $\begin{array}{l}\text { Concentra a modelagem hermenêutica. É uma rotina } \\
\text { de análise de registros que produz redes de } \\
\text { significados organizados e aptos a representar o } \\
\text { espaço, composto pelos atos de interpretar e desenhar }\end{array}$ & $\begin{array}{l}\text { - Identificar conceitos chaves } \\
\text { - Aplicar critérios definidos aos itens } \\
\text { colecionados. } \\
\text { - Caracterizar os elementos aprovados segundo } \\
\text { os critérios }\end{array}$ \\
\hline Construir & $\begin{array}{l}\text { Reúne as ações de manipulação dos elementos de um } \\
\text { espaço de informação. É um conjunto de ações finitas } \\
\text { e planejadas que servirão de base para a transformação } \\
\text { do espaço }\end{array}$ & $\begin{array}{l}\text { - Determinação de classes, atributos e } \\
\text { relacionamentos } \\
\text { - Exercitar modelagem estática } \\
\text { - Exercitar modelagem dinâmica } \\
\text { - Implementar a ontologia }\end{array}$ \\
\hline Habitar & $\begin{array}{l}\text { Momento em que o sujeito usa o espaço de informação } \\
\text { percebido, modelado e aperfeiçoado conforme suas } \\
\text { intenções. É a incorporação de espaço pelo sujeito } \\
\text { pelos atos de transformar e estar. }\end{array}$ & $\begin{array}{l}\text { - Certificar-se que os usuários compreenderam a } \\
\text { ontologia } \\
\text { - Criar um espaço de aprendizado do modelo }\end{array}$ \\
\hline
\end{tabular}

Fonte: Adaptado de BEIRA (2015) e COSTA (2009).

Mendonça, Cardoso e Drumond (2010) apontam Método 101 como um dos roteiros para a construção de ontologias mais difundidos. Destaca ainda que a aplicação conjunta do Método 101 com o Protégé tem apresentado bons resultados para apoiar a construção destes artefatos, revelando um processo de fácil estruturação e representação formal do conhecimento.

A Figura 2 exibe o ciclo sequencial proposto para os momentos do MAIA, sobre os quais foram projetadas as etapas da Metodologia 101, para exemplificar a adequação entre os modelos e seu potencial de uso para a AI. Por este e pelos outros motivos anteriormente aqui expostos, principalmente em razão da fundamentação científica de seu constructo, 0 MAIA foi utilizado na metodologia do presente trabalho.

Beira (2015) defende que, no ato de "habitar" o espaço da informação da ontologia, o exercício da modelagem estática e da modelagem dinâmica pode ser realizado através da adequação dos Atos de Transformação. Se todos os atos (transformações e relações) aplicáveis podem ser descritos em termos dos entes mapeados, então a ontologia é adequada ao propósito pretendido; caso contrário, a ontologia é incompleta ou inadequada. 
Figura 2 - Ciclo do MAIA e Metodologia 101 (destacado em azul)

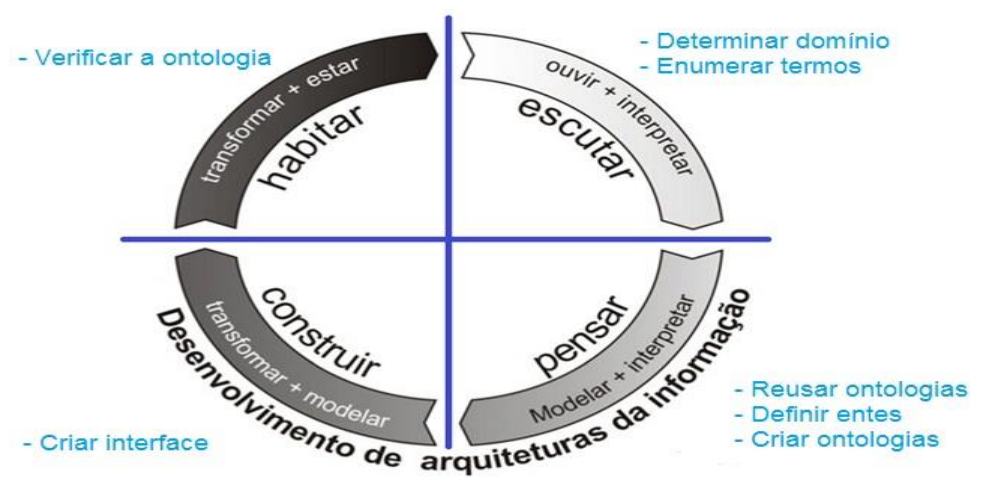

Fonte: Adaptado de COSTA (2009) e NOY; MCGUINESS (2000).

\subsection{Integração de conceitos}

A CS orienta para a melhoria da qualidade na gestão pública e, por esta razão, foi o referencial a orientar a ontologia a ser construída. Da mesma forma, espera-se que a aplicação seja contínua e tenha alcance na organização. Em outras palavras, espera-se que a ontologia seja eficaz e efetiva, razão pela qual as plataformas wikis foram agregadas ao referencial.

As wikis foram selecionadas por três aspectos essenciais à GC: alcance, escala e colaboração. Para que a GC seja eficiente, é necessário que o maior número possível de colaboradores tenha fácil acesso ao conteúdo explicitado. Na dimensão alcance, elas podem virtualmente atingir qualquer colaborador, tanto quanto ao acesso, quanto pela linguagem. Assim, espera-se que haja melhora nas relações internas e que esta impacte significativamente os serviços externos e auxilie o cidadão e as instituições a exercer seus direitos e controle social.

Nesta pesquisa, o conjunto/modelo ontologia+wikis será considerado um espaço de informação (SIQUEIRA, 2012) e, por esta razão, será construído por meio dos conceitos propostos pelo MAIA. Quanto à utilização posterior na organização, entende-se que a GC ocorrerá segundo os princípios defendidos por Batista (2012). Ainda que a avaliação dos autores seja divergente, entende-se que as teorias serão aplicadas em escopos diferentes.

\section{Metodologia}

O presente artigo descreve os resultados de uma pesquisa qualitativa, aplicada e metodológica, referente à elaboração de um instrumento de captação da realidade que busca resolver também um 
problema concreto. Foi desenvolvida uma ontologia de domínio, a OntoCSI, versando sobre serviços internos e baseada em estudo realizado na área de recuperação de créditos da CAIXA Econômica Federal (CAIXA). O objetivo do estudo é reter o conhecimento sobre o domínio estudado buscando evitar sua perda e reduzir o tempo médio requerido para acessá-lo.

O processo foi dividido em cinco etapas, enumeradas de " $A$ " à " $E$ ", segundo o ciclo MAIA: A etapa " $A$ " teve o objetivo de identificar os elementos e conceitos fundamentais ao problema de pesquisa, bem como as estruturas relacionadas ao conceito de serviços internos, representando - momento "escutar" e seu produto final foi uma lista abrangente de termos e definições. A etapa seguinte foi a execução de entrevistas semiestruturadas no ambiente da organização escolhida para alcançar as relações, classes e hierarquias entre tais conceitos, ainda relacionada ao instante "escutar". Nesta fase os termos da etapa " $A$ " foram apreciados para identificação de divergências e convergências, bem como triangulação das informações pesquisadas na literatura e nos documentos.

De acordo com o que é explicado mais adiante, os dados e informações das etapas " $A$ " e " $B$ " foram utilizados para a montagem da ontologia, atividade fim da etapa " $C$ ", que também integra os pontos comuns levantados na literatura, caracterizando o momento "pensar". No momento "construir", etapa "D", as classes diretamente ligadas à CSI foram utilizadas para instanciar elementos na plataforma wiki da organização escolhida, criando um ambiente para visualização do modelo proposto. Nela estão disponíveis as CSI de algumas atividades e uma forma de navegação que represente os ideais propostos. Este mesmo ambiente wiki piloto foi utilizado na etapa " $E$ ", submetido a especialistas da área de recuperação de créditos e rede e agências para checar sua adequação à realidade, momento "habitar".

\subsection{Etapa A: análise documental e bibliográfica}

Durante a fase inicial do MAIA, momento "escutar", foi realizada uma busca na base CAPES sobre conceitos de serviços internos, operação de crédito, produtos, recuperação e manutenção de créditos por palavraschaves como adimplência, e etc. Foi realizada, também, pesquisa a documentos internos e manuais normativos da CAIXA, bem como a normas e resoluções do Banco Central do Brasil (BACEN) e de BASILÉIA .

Ao final das análises nestes documentos, foram identificados elementos que deram suporte à estruturação da ontologia sobre o domínio em questão, permitindo a identificação de conceitos, atores, relações básicas, processos, práticas, ferramentas utilizadas, indicadores e mecanismos de relações entre os atores. Observou-se que os subconjuntos "Oferta de serviços", "Negociação dos serviços" e "Execução do serviço" abrangem as principais conceituações encontradas na literatura (desde as definições clássicas da administração até os modernos 
conceitos de serviços eletrônicos) e se adequam ao modelo da instituição estudada.

Adicionou-se ao conjunto de conceitos acima: definições encontradas na ontologia sobre CS (LOPES; NÓBREGA; PACHECO, 2014); definições das CS de grandes instituições públicas (BACEN, TSE e INMTERO, por exemplo); seis normativos internos à instituição;modelos de dados de três sistemas de informação (SI) da organização que envolvem demandas entre unidades (sistemas de demandas); duas premissas de BASILÉIA; e publicação da GESPUBLICA sobre CS (BRASIL, 2008).

\subsection{Etapa B: realização de entrevistas semiestruturadas}

Em uma segunda etapa, ainda relacionada ao momento "escutar", foi realizada a aplicação de um questionário semi estruturado com perguntas relacionadas às premissas e objetivos deste trabalho. Procurouse capturar o perfil básico dos entrevistados, sua concordância com a visão sobre os processos baseada em serviços e seu nível de conhecimento e concordância com a proposta do projeto.

Os termos foram avaliados do seguinte modo: cada entrevistado recebia uma lista de 10 termos dentre os 50 disponíveis, de forma sequencial, na qual sempre estavam incluídos os conceitos principais "Serviço como Compromisso / promessa / obrigação" e "Serviço como demanda / pedido" e avaliava se havia concordância com a definição, propondo alterações se necessário, e realizando uma avaliação da importância e relevância do mesmo para seu contexto de trabalho.

Foi utilizada uma escala likert de 6 níveis ( 0 a 5 ), sendo " 0 " correspondente a "não é importante/relevante" e "5 - muito relevante/importante". Foi questionado ainda se algum termo deveria ser adicionado à relação, alterado ou excluído, do contexto. Já a segunda parte da entrevista foi formada de questões abertas e de questões com utilização de escala likert de cinco níveis. Seu objetivo principal foi compreender se a visão de serviços sobre as atividades entre unidades na organização, alinhada às perspectivas de GC eram adequadas.

Nesta fase, enquanto ainda se procuravam elementos para auxiliar na compreensão do domínio da ontologia, realizou-se inicialmente uma amostra piloto com cinco candidatos para checar a consistência e o entendimento das perguntas, fato ocorrido entre 17/08/2015e 19/08/2015. Após as correções, foram realizadas 31 entrevistas entre 24/08/2015 e 04/09/2015. Procurou-se atingir cargos estratégicos na área de recuperação de crédito (Gerentes Executivos e Nacionais, e seus consultores principais) da instituição estudada e voluntários da rede de atendimento ao cliente.

O objetivo das entrevistas foi informado no seu início, junto com uma contextualização sobre o domínio. Elas foram gravadas, permitindo aos entrevistados explorem seus pontos de vista conforme sua necessidade. Ao final, as questões objetivas foram aliadas segundo sua média ou proporção. Já as perguntas subjetivas foram anotadas em sua 
completude e reduzidas gradualmente, em vários ciclos, para agrupar as definições semelhantes.

\subsection{Etapa C: modelagem conceitual da ontologia}

Para modelagem da ontologia, foi utilizada a metodologia do MAIA, criado por Costa (2009) e formada por quatro momentos (escutar, pensar, construir e habitar), conforme já exposto. Como ferramenta, foi utilizado o Protégé versão 4.3.0, criado pela Universidade Stanford e amplamente utilizado em trabalhos na área pela facilidade de uso e opções disponíveis, com linguagem OWL 2.0.

Para orientar a criação dessa ontologia, foi utilizada a ontologia fundamental UFO-S sobre serviços (NARDI et al., 2015). De acordo com a literatura, as ontologias de fundamentação e de núcleo, como esta, são essenciais para a reutilização e coerência da ontologia de domínio. Mostrou-se necessário ainda uma ontologia específica sobre organizações, sendo utilizado o modelo TOVE de Fox, Barbuceanu e Grunninger (1997). Adicionalmente às ontologias de domínio sobre CS de Lopes, Nóbrega e Pacheco (2014) e alguns conceitos sobre compartilhamento em wiki foram referenciados, conforme Figura 3.

Figura 3 - Esquema de referência das ontologias

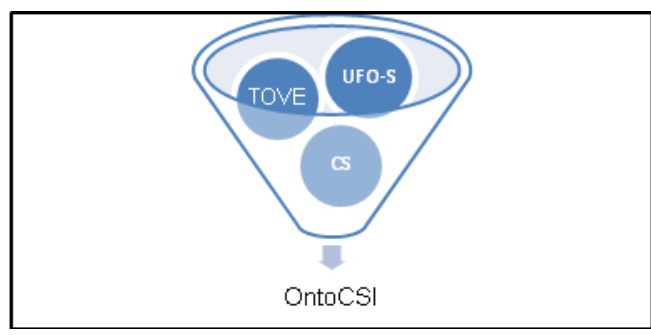

Fonte: Elaboração própria.

Nesta etapa do estudo, procurou-se construir um modelo de conhecimento ontológico para a CSI. O momento "construir" reúne ações de manipulação dos elementos do espaço de informação e reúne um conjunto de ações finitas e planejadas que servirão de base para a transformação do espaço, entre elas: exercícios de modelagem e determinação de classes, atributos e relacionamentos (COSTA, 2009).

\subsection{Etapa D: criação do piloto wiki}

Prosseguindo no momento "construir" e caminhando para o momento "habitar", nesta etapa do estudo procurou-se modelar o espaço de informação percebido e aperfeiçoado conforme as etapas anteriores (COSTA, 2009), através da implementação do modelo proposto na ontologia via ambiente wiki. Utilizaram-se as classes ontológicas referentes à CSI em si como diretrizes para a criação de páginas na wiki 
Formalização de serviços internos em grandes corporações: Proposta de ontologia para construção colaborativa de Carta de Serviços
Maurício Telles Bígio; Remis Balaniuk; Ana Paula Bernardi da Silva; Vitória Santiago da Silveira

corporativa da instituição estudada. As páginas foram confeccionadas em $15 / 10 / 2015$ e cumpriram o papel de projeto piloto para o modelo proposto pela ontologia, materializando a CSI, ao mesmo tempo em que possibilitaram novamente captar o ponto de vista dos pesquisados acerca da mesma.

Segundo a ontologia sobre CSI, a oferta de serviços deve conter um conjunto de propriedades para que seu objetivo seja cumprido. Estas propriedades estão listadas na Tabela 2 e constituem o ponto de partida do piloto.

Tabela 2 - Propriedades da oferta de serviços

\begin{tabular}{l|l}
\hline \multicolumn{1}{c}{ Conceito } & \multicolumn{1}{c}{ Descrição } \\
\hline \hline Acessibilidade & Facilidade de acesso e familiaridade com a linguagem e o ambiente \\
\hline Alcance & Capilaridade, capacidade de chegar ao maior número de pontos na organização \\
\hline $\begin{array}{l}\text { Atualização } \\
\text { constante }\end{array}$ & Atualização de conteúdo para que o mesmo siga válido e útil durante o tempo \\
\hline Clareza & Linguagem simples e acessível \\
\hline $\begin{array}{l}\text { Grau } \\
\text { detalhamento }\end{array}$ & Detalhamento relacionado a descrição do serviço \\
\hline $\begin{array}{l}\text { Plataforma } \\
\text { Possibilidadede } \\
\text { pesquisa }\end{array}$ & Local aonde se dará a oferta do serviço \\
\hline $\begin{array}{l}\text { Terminologia } \\
\text { comum }\end{array}$ & Uso compartilhado de termos para evitar ambiguação do entendimento de termos e conceitos \\
\hline \begin{tabular}{l} 
Utilidade \\
\multicolumn{2}{l}{ Potencial de ser útil no cotidiano da organização } \\
Fonte: Dados da pesquisa.
\end{tabular} \\
\end{tabular}

O grau de detalhamento foi constituído conforme entrevista semiestruturada das etapas anteriores, considerado como descrever até o "know-how" da atividade/serviço e a utilidade será tanto maior quanto maior for a descrição dos processos mais importantes da organização, pois um dos objetivos da GC é corroborar com a estratégia da organização (BATISTA, 2008). A metodologia para obter a lista destes processos críticos foi abordada sem seu trabalho.

\subsection{Etapa E: avaliação da ontologia}

Para a avaliação da ontologia, a mesma foi submetida aos profissionais especialistas da área de recuperação de créditos e de gestão do conhecimento da CAIXA para checar sua adequação à realidade. Ressalta-se que a ontologia foi avaliada indiretamente, pois sua avaliação foi realizada através de seu reflexo na aplicação wiki piloto. Esta etapa corresponde ao momento "habitar", em que o sujeito usa o espaço de informação percebido, modelado e aperfeiçoado conforme suas intenções. É a incorporação de espaço pelo sujeito pelos atos de transformar e estar (COSTA, 2009). É necessário certificar-se que os usuários compreenderam a ontologia e criar um espaço de aprendizado do modelo.

Para cumprir estes objetivos, realizou-se enquete eletrônica com os funcionários interessados (comunidade de clientes) nos dois serviços descritos sobre o Sistema Integrado de Gestão de Ativos (SIGA). Foram abordados os próprios usuários do sistema, em sua tela de login, entre $15 / 10 / 2015$ e 15/11/2015, com um total de 12.024 respostas. 
Adicionalmente, solicitou-se que uma das quatro gerências nacionais envolvidas descrevesse de forma independente suas atividades segundo o modelo proposto neste trabalho, avaliando ainda se a forma de construção de novas CSI está adequada.

\section{Resultados e discussão}

Durante a execução da pesquisa, chegou-se a uma lista de 50 termos relacionados ao tema de serviços internos, termos estes originados de pesquisa a documentos e normas internos da CAIXA, bem como a resoluções do BACEN e de BASILÉIA. Percebeu-se que não há uma determinação clara quanto à realização de tarefas entre unidades. No entanto, segundo o acordo de BASILÉIA, o Conselho de Administração de um banco tem a responsabilidade de assegurar que a gestão estabeleça um sistema para avaliação dos diversos riscos e defina um método para o controle do cumprimento das políticas internas.O conselho deve verificar regularmente se o seu sistema de controles internos é adequado para garantir a bem ordenada e prudente conduta dos negócios.

Percebe-se, então, o potencial da correta definição e divulgação de serviços internos na organização, especialmente nas maiores, para o cumprimento deste acordo fundamental. As próximas seções detalham os resultados a as percepções encontradas durante as etapas do presente artigo.

\subsection{Caracterização amostral}

Seis estados compuseram a amostra: Acre, Distrito Federal, Minas Gerais, Paraná, Rio Grande do Sul e São Paulo. Sendo a capital o maior representante, 65\%. Dos 31 entrevistados, 23 possuíam função gerencial, em média com nove anos de experiência em gestão. As funções exercidas variaram desde Gerente Geral de agência até Superintende Nacional. Os demais entrevistados possuíam cargos técnicos de Consultor (também conhecidos como Especialistas em outras organizações), alguns com experiência em substituição de gestores.

A Tabela 3 exibe a distribuição por tipo de unidade/departamento. A Agência representa a unidade de "ponta", a Centralizadora Nacional e a Gerência de Filial as unidades "meio" e as demais as unidades estratégicas (matriz da instituição). A diversidade de unidades é interessante para compor a visão ontológico proposta.

Tabela 3 - Distribuição da entrevista por tipo de unidade

\begin{tabular}{|c|c|}
\hline Tipo de unidade & Quantidade de entrevistas \\
\hline Agência & 2 \\
\hline Centralizadora Nacional & 3 \\
\hline Gerência de Filial & 9 \\
\hline Gerência Nacional & 14 \\
\hline Superintendência Nacional & 3 \\
\hline Total Geral & 31 \\
\hline
\end{tabular}

Fonte: Dados da pesquisa. 


\subsection{Lista inicial de termos}

A média geral das avaliações de cada termo foi de 4,5. Apenas o conceito "Segunda instância/ regulador" teve avaliação inferior a 4 e, desta forma, foi retirado da proposta de ontologia. Adicionalmente, a descrição de "hierarquia" foi alterada e a de "inovação" incluída. Os dois conceitos principais, serviço como compromisso, promessa ou obrigação e serviço como demanda ou pedido, tiveram avaliação média de 4,5 e 4,6, respectivamente, indicando aderência potencial com o projeto de pesquisa. Estes termos integraram o modelo de conhecimento proposto e a relação entre eles está descrita mais a frente.

\subsection{Demais resultados do questionário}

$90 \%$ dos entrevistados concordou que os processos da instituição podem ser vistos sob a ótica de serviços e concordam que a unidade é dependente de outras unidades para realizar suas tarefas. A Tabela 4, a seguir, exibe os termos mais citados para definir qualidade na prestação de um serviço no contexto de trabalho da amostra.

Tabela 4 - Fatores para a execução de um serviço de qualidade

\begin{tabular}{|c|c|}
\hline Aspecto & Citações \\
\hline Eficiência & 17 \\
\hline Eficácia & 9 \\
\hline Domínio (know-how) & 6 \\
\hline Controle & 4 \\
\hline Clareza & 4 \\
\hline Estrutura/recursos & 4 \\
\hline Fundamentação & 4 \\
\hline Papéis e responsabilidades & 4 \\
\hline Atitude & 3 \\
\hline Cordialidade & 3 \\
\hline Outros & 13 \\
\hline
\end{tabular}

Fonte: Dados da pesquisa.

Os entrevistados concordam que é verdadeiro o impacto da prestação de serviços entre unidades sobre o cliente final da instituição, mas expressam preocupação sobre o monitoramento da mesma. Este subconjunto reforça o resultado mostrado na Tabela 4, pois os dois itens mais citados como necessários para um serviço de qualidade foram justamente "Eficácia, resolver o problema adequadamente e completamente" e "Eficiência, atender o pedido no prazo estipulado".

Já quanto à existência de um padrão corporativo para descrever os serviços ou atividades de uma unidade, $48 \%$ consideram que não existe um padrão e $41 \%$ acreditam que este padrão é parcial ou não é respeitado. Em se tratando apenas da unidade dos entrevistados, metade citou sistemas de demandas como forma de obter tal informação e 32\% afirmaram não possuir (só utilizam o e-mail corporativo para trafegar tal informação). Outras citações foram Acordos de Nível de Serviço (ANS), 
Formalização de serviços internos em grandes corporações: Proposta de ontologia para construção colaborativa de Carta de Serviços
Maurício Telles Bígio; Remis Balaniuk; Ana Paula Bernardi da Silva; Vitória Santiago da Silveira

manuais normativos, páginas da intranet de unidades e reuniões eventuais.

23 entrevistados concordam que não existe um catálogo ou forma de divulgação sistemática dos serviços que as unidades prestam umas às outras e entendem que tal informação é obtida. O item "Pesquisa generalizada" citado é a utilização de e-mail e telefone para obtenção da informação, acionando várias unidades no processo. Já os demais, entendem que os catálogos são os próprios manuais normativos (regras corporativas) e sistemas de demanda, atualizados somente sob encomenda. Este item do questionário evidencia como a ausência do catálogo sobre serviços ocasiona uma utilização de recursos (inclusive o tempo) para obtenção da informação sobre serviços internos.

A nota para a importância do catálogo foi de 4,8, corroborando as citações constatadas no referencial deste trabalho. O catálogo aqui se refere a uma forma organizada de obter os serviços prestados por uma organização pública ou unidade da mesma, que funcione como um ponto focal para o tema. Quanto ao detalhamento dos serviços nos catálogos, $25 \%$ da amostra entende que a descrição deve ser superficial e $75 \%$ que deve ser detalhada, sendo que metade destes últimos considera importante dividir o detalhamento em níveis ou perfis de acesso.

A descrição do know-how é um aspecto essencial no registro dos serviços, com nota 4,3. Destaca-se que os entrevistados elegeram "Continuidade" e "Padronização" como itens mais importantes, citando a manutenção do conhecimento dentro do primeiro conceito e revelando novamente as premissas de GC. Ressalta-se, ainda, que os seis gerentes com mais de 15 anos de experiência entendem que não há catalogação e $70 \%$ se preocupam com a continuidade dos serviços.

Quanto ao prejuízo causado pela ausência de descrição/catalogação de serviços entre unidades, sua divulgação e/ou a falta de uma política institucional para tal, $85 \%$ da mostra considerou-se impactada. Poucos entrevistados citaram valores absolutos. No entanto, atrasos generalizados foram citados 19 vezes, necessidade de orientação dos demandantes e redirecionamento para outras unidades foi citada 11 vezes e retrabalho outras oito vezes. Outros itens foram: interrupções, multas, ações judiciais, desgastes pessoais, desmotivação, perda de qualidade e de conhecimento.

Foi questionado, ainda, quais serviços da unidade dos entrevistados suscitam mais dúvidas às unidades demandantes, a maioria (35\%) citou bases e sistemas, 22\% alçadas, papéis e responsabilidades e outros $22 \%$ afirmam ser um problema generalizado. A instituição como um Banco Público é muito intensiva em TI, no entanto há entraves para uso da informação de forma consistente e leva à aferição acima.

$\mathrm{Na}$ Tabela 05 estão listados os resultados das questões de número 18 a 24. O objetivo destas perguntas foi avaliar a aderência do modelo proposto com a realidade dos entrevistados. Percebeu-se que a CS não é familiar para a grande maioria, apesar de bem avaliada quando apresentada. A wiki tem boa familiaridade e os entrevistados 
Formalização de serviços internos em grandes corporações: Proposta de ontologia para construção colaborativa de Carta de Serviços
Maurício Telles Bígio; Remis Balaniuk; Ana Paula Bernardi da Silva; Vitória Santiago da Silveira

consideraram viável e útil a construção do modelo proposto por este trabalho.

Tabela 5 - Resumo da avaliação do potencial do modelo

\begin{tabular}{l|c}
\hline \multicolumn{1}{c}{ Questão } & Avaliação \\
\hline \hline $\begin{array}{l}\text { Você avalia que uma forma mais PADRONIZADA E CLARA de registro dos serviços poderia } \\
\text { auxiliar para obter tal informação de forma mais rápida e melhorar o atendimento do cliente } \\
\text { final? }\end{array}$ & 4,8 \\
\hline $\begin{array}{l}\text { É usual para você o conceito da carta de serviços? (*A CS foi apresentada a todos após esta } \\
\text { questão) }\end{array}$ & \multirow{2}{c}{3,3} \\
\hline \begin{tabular}{l} 
É usual para você o conceito de ambiente wiki para construção colaborativa de conhecimento? \\
\hline $\begin{array}{l}\text { Você avalia que funcionários de outras unidades poderiam contribuir com a descrição dos serviços } \\
\text { da sua unidade? }\end{array}$
\end{tabular} \\
\hline $\begin{array}{l}\text { Você considera viável combinar o modelo de carta de serviços e wiki corporativa para criar um } \\
\text { catálogo compartilhado de serviços internos? }\end{array}$ & 4,1 \\
\hline Como você avalia a utilidade potencial desse ambiente para o atendimento entre unidades? & 4,5 \\
\hline Como você avalia o impacto potencial desse ambiente para o atendimento do cliente final? & 4,5
\end{tabular}

Fonte: Dados da pesquisa.

\subsection{Momento construir I: construção da ontologia (ontoCSI)}

Nos próximos parágrafos, serão exibidas as principais bases da ontologia de domínio criada, a OntoCSI. Os termos criados especificamente para esta ontologia receberão a notação *o após sua citação. E para evidenciar os termos herdados de UFO-S e de TOVE para organizações, serão incluídas as notações $*^{\mathrm{s}} \mathrm{e}^{* \mathrm{t}}$, respectivamente.

Na Figura 4 é possível observar o serviço interno caracterizado como uma atividade $\left({ }^{\mathrm{t}}\right.$, classe originada de TOVE) dentro da organização $\left({ }^{\mathrm{t}^{\mathrm{t}}}\right)$, a atividade de prover ou fornecer um serviço $\left({ }^{* s}\right)$ : a classe Provide internal service $\left({ }^{* 0}\right)$. Esta atividade ocorre entre duas divisões/unidades $\left({ }^{* t}\right)$ e, dentro delas, pessoas (OrganizationAgent, ${ }^{* t}$ ) desempenham o papel $\left(\right.$ Role, ${ }^{* t}$ ) de cliente (Internal service customer, ${ }^{*} \mathrm{~s}$ ) ou de fornecedor (Internal service provider, *s).

Neste ponto, há uma junção entre os conceitos de TOVE e da UFO$\mathrm{S}$, pois as divisões $(* \mathrm{t})$ assumem, eventualmente, os atributos de Hired Service Provider $\left({ }^{*} s\right)$ ou de Service Customer $\left({ }^{*} s\right)$. Isto é essencial para o OntoCSI, pois não se pretendeu reescrever os conceitos sobre serviço, apenas aplicá-los ao contexto de organizações. Observa-se ainda que a unidade fornecedora do serviço interno requer determinadas habilidades/conhecimentos (Skills, *t) para executá-los e estas habilidades estão ligadas ao papel (role, $\left.{ }^{*} s\right)$ desempenhado pelas pessoas lotadas em tal unidade.

Figura 4 - OntoCSI - Serviço como atividade 


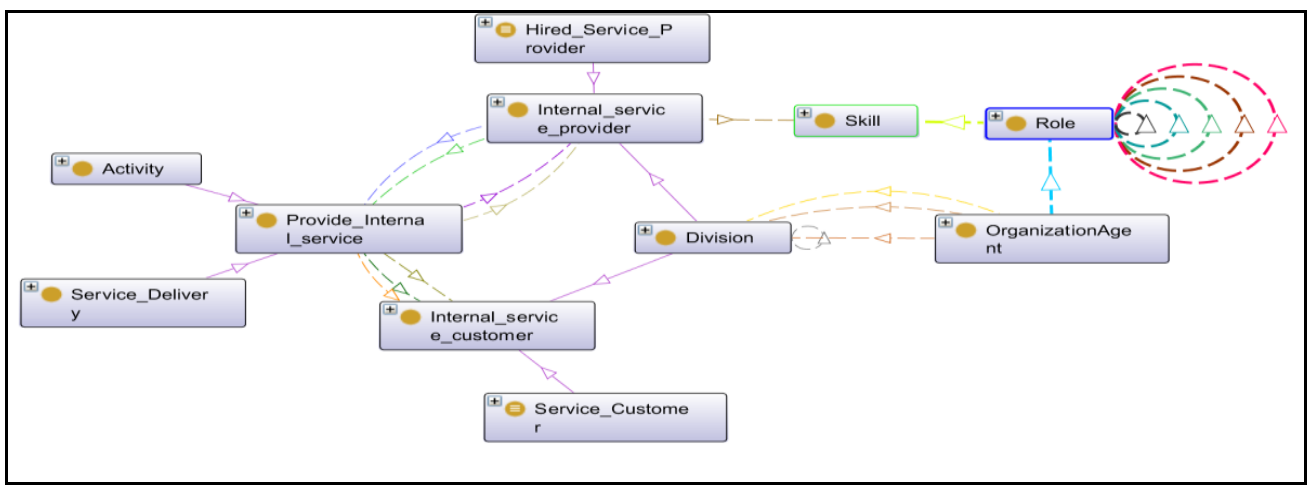

Fonte: Elaboração própria.

A título de exemplo, pode-se imaginar uma organização em que ocorra o processo de ajuizamento de dívidas. Uma unidade jurídica pode necessitar de subsídios para a correta apresentação do caso junto à justiça e desempenha o papel de unidade cliente ao solicitar que uma unidade de negócio forneça a caracterização da dívida, o histórico de acionamento do cliente e propostas de acordo.

A entrega do serviço modifica a realidade, recursos $(* t)$, tangíveis ou não, são utilizados para geração de um valor. Este valor pode ser agregado a um bem que já existia, pode ser a alteração da situação de um contrato (de normal para ajuizado ou liquidado e etc.) ou até mesmo representar um novo nível de entendimento da realidade (seria o caso de fornecimento de informações). Esta alteração da realidade causada pelo atendimento ou provisão do serviço interno recebe o nome de Service state $(* 0)$, conforme Figura 5. TOVE nos fornece outros tipos de alteração da realidade, não abrangidos neste tema, states $(* t)$.

Figura 5 - OntoCSI - Service state

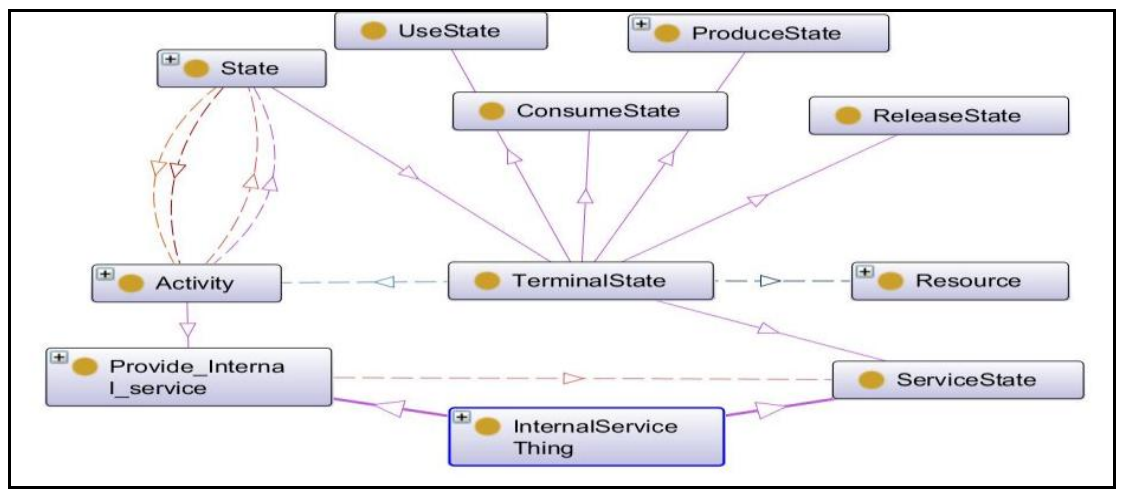

Fonte: Elaboração própria.

O Negócio da organização naturalmente gera demanda por novos serviços e uma oferta surge para atendê-la, uma vez que tenha sido negociada (*s) a forma como a demanda será atendida. A oferta de serviços (Service Offering Commitment, ${ }^{*}$ ) s se constitui basicamente da descrição da forma de execução do serviço e da catalogação destes. A Figura 16mostra esta oferta na visão dos serviços internos, o conjunto dos serviços oferecidos por uma divisão estão descritos em sua Carta de 
serviços internos (InternalServiceCharter, *o), que, por sua vez, é formada por itens (InternalServiceCharterItem, *o).

A unidade cliente precisa atender os Requisitos (Requirements, *o) descritos na carta e tem como contrapartida a publicidade de todos os outros atributos sobre o procedimento (Component ofInternalServiceCharterItem, o*), canais, prazos, norma referenciada e outros. Cada item da carta de serviço descreve um único serviço interno e os seus componentes devem ser sempre os mesmos, seguindo um parâmetro determinado, para que haja padronização na informação disponibilizada.

A classe Internal Service Category (*o) se refere a uma classificação segundo o contexto da instituição para organização das Cartas de Serviço e para futura recuperação das informações na plataforma escolhida. Já a classe Internal service access point (*o) é uma referência ao canal específico para acessar um serviço e para receber a resposta do mesmo.

A própria constituição da Carta de Serviços Internos possui diretrizes para sua construção (ServiceCharterEvaluation, *o) de forma a atender a premissa de contribuir com a melhora da qualidade da prestação de serviços dentro da organização e para o cidadão. A CSI deve descrever um serviço de formaaesclarecer o máximo sobre ele. Entretanto, a descrição não deve ser muito profunda, para permitir um entendimento rápido e claro sobre o mesmo, com exceção do "como fazer" o serviço. Este item deve ter o passo-a-passo detalhado sobre como executar esta atividade, mantendo a clareza na descrição, para a memória organizacional.

Os itens alcance, Acessibilidade, Plataforma, Terminologia comum, Possibilidade de pesquisa e Atualização constante (*o) podem ser providos pela plataforma wiki, prevista no modelo.Este ambiente possui grande aderência com as propostas da CSI e tem potencial de se integrar as atividades do cotidiano sem se constituir como uma nova rotina. $E$, apesar de haver outras formas de suprir estas necessidades, estes métodos podem se revelar trabalhosos, de alto custo, ou pouco eficientes. A Figura 6 apresenta o conjunto de diretrizes da CSI.

Figura 6 - OntoCSI - Diretrizes da CSI

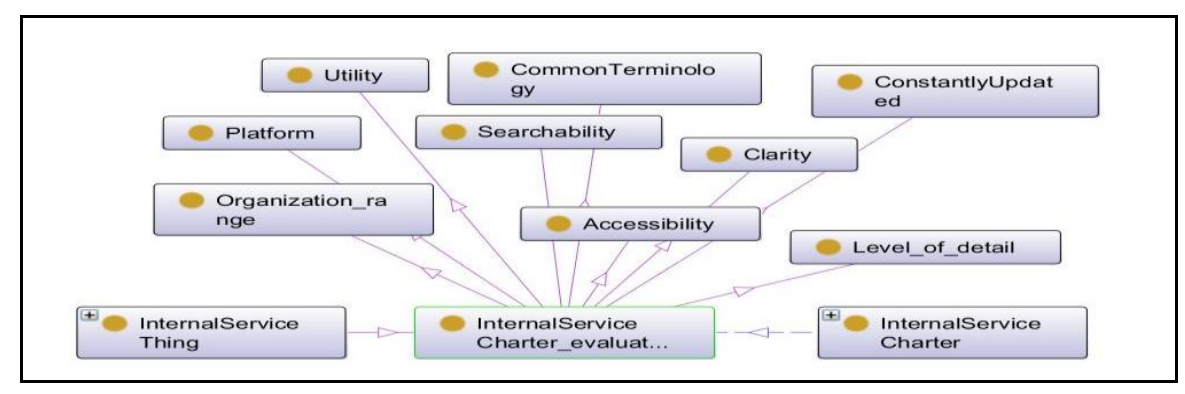

Fonte: Elaboração própria.

Já a Figura 7 mostra as características de execução de um serviço (Provide internal servisse, *o). É interessante notar que estes itens (qualidade, transparência, eficácia..., *o) são itens objetivos esperados 
para o cumprimento dos serviços e podem ser utilizados para o seu monitoramento, independentemente do contexto. É evidenciado ainda que a GC atua positivamente sobre estas propriedades, a divulgação das informações, o monitoramento e o controle coletivo permitem que a comunidade de clientes exija condições de atendimento por conhecerem suas premissas.

Figura 7 - OntoCSI - Propriedades da execução do serviço

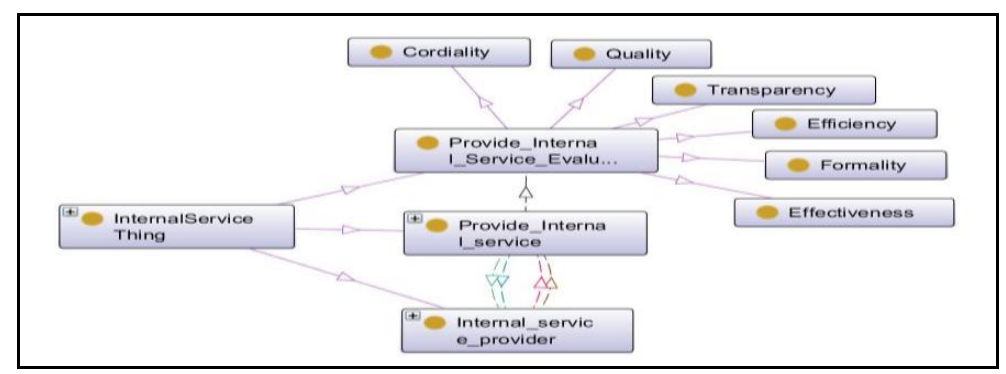

Fonte: Elaboração própria.

É importante notar que a ontologia foi criada a partir da visão de um conjunto limitado de recursos e isto limita sua generalização, como citado por Grenon (2009) há a percepção de que os serviços são sensíveis ao tipo de atividade em que ocorrem e podem ser analisados sob diferentes perspectivas. Adicionalmente, foi analisada apenas uma organização. No entanto, como a ontologia criada carrega o conhecimento sobre os conceitos e sobre o contexto utilizados, pode ser reavaliada em outros contextos para utilização futura. O modelo foi disponibilizado na biblioteca web do Protégés.

\subsection{Momento construir II: demais termos e suas relações}

Constituem o modelo de conhecimento OntoCSI 18 propriedades ontológicas não herdadas de UFO-S ou TOVE para organizações. As principais estão listadas a seguir. Quando um termo não listado for citado, sua descrição será adicionada a citação da propriedade. Os subtítulos serão organizados conforme o original no padrão: domínio, propriedade e escopo.

\subsubsection{InternalServiceCharterItem describes Provide_Internal_Service}

Prover um serviço interno é atender as demandas/solicitações entre unidades/departamentos de uma organização, enxergando-as sob a ótica de serviços. A forma de acessar e atender este serviço, os compromissos de atendimentos (prazo, local de atendimento e outros) são descritos por um item da CSI de uma unidade organizacional. No exemplo da UFO-S, em um contrato de aluguel de carro, prover um carro em condições de uso, substituí-lo em caso de falha, pagar o aluguel do carro e pagar por

\footnotetext{
${ }^{3}$ Disponível em: <http://www.semanticweb.org/ontologies/2015/10/OntoCSI>. Acesso em: 15 set. 2015.
} 
Formalização de serviços internos em grandes corporações: Proposta de ontologia para construção colaborativa de Carta de Serviços
Maurício Telles Bígio; Remis Balaniuk; Ana Paula Bernardi da Silva; Vitória Santiago da Silveira

danos ocorridos no veículo são parte da descrição do serviço. Os axiomas da OntoCSI estão listados na Tabela 06.

Tabela 6 - Axiomas de OntoCSI

\begin{tabular}{ll}
\hline OS01 & Serviço interno é uma atividade (que, por sua vez, faz parte de um processo maior) \\
\hline OS02 & $\begin{array}{l}\text { Serviço interno é realizado entre duas divisões/unidades (divisions) e, dentro delas, pessoas desempenham } \\
\text { o papel (role) de cliente (customer) ou de fornecedor (provider) }\end{array}$ \\
\hline OS03 & O fornecedor precisa de determinadas habilidades (skills / know-how) \\
\hline OS04 & $\begin{array}{l}\text { O cliente precisa atender os requisitos descritos no item da carta de serviço } \\
\text { (Service_Offering_Commitment) }\end{array}$ \\
\hline OS05 & A entrega do serviço (service delivery) modifica a realidade (state, service state) \\
\hline OS06 & $\begin{array}{l}\text { O conjunto dos serviços oferecidos por uma divisão estão descritos em sua Carta de serviços internos, que, } \\
\text { por sua vez, é formada por itens. }\end{array}$ \\
\hline OS07 & Cada item da carta de serviço descreve um serviço interno \\
\hline OS08 & Os itens da carta de serviços interno devem ser sempre os mesmos, seguindo um parâmetro determinado \\
\hline OS09 & A entrega do serviço (service delivery) tem propriedades esperadas \\
\hline OS10 & A Carta de Serviços Internos possui diretrizes para sua construção \\
\hline
\end{tabular}

Fonte: Dados da pesquisa.

\subsubsection{Internal_Service_Category groups Provide_Internal_Service}

Os serviços internos podem ser agrupados em termos de categorias negociais. Estas categorias representam similaridade entre os serviços ou proximidade de contexto entre eles. A título de exemplo, serviços relacionados a contas bancárias podem constituir uma categoria negocial de Resgate e aplicação, enquanto serviços relacionados a empréstimos podem constituir uma categoria de Financiamento. Os serviços podem fazer parte de mais de uma categoria simultaneamente, os exemplos citados podem constituir uma categoria de Contratos comerciais.

Esta propriedade ontológica é essencial para a aplicação em ambiente wiki, pois as categorias desta plataforma agrupam, da mesma forma, seu conteúdo, facilitando a organização e, consequentemente, a localização. Adicionalmente, é um agrupamento natural nas organizações.

\subsubsection{Internal_Service_Provider has_exclusive_skills Skill}

A unidade ou divisão que provê um determinado serviço interno precisa adquiri conhecimentos e habilidades exclusivas para 0 atendimento de tal serviço. Ainda que a habilidade não seja exclusiva daquela unidade específica, ela será para o tipo de unidade em questão. TOVE para organizações define skill como uma ou mais habilidades necessárias para a realização de um papel.

Esta é outra propriedade natural nas organizações, conforme ocorre especialização das atividades, essencial ao modelo, pois a GC deve ocorrer neste contexto para manter as unidades funcionais e os serviços com padrão de qualidade elevado. É pretendido mitigar efeitos de rotatividade 
e outras fontes de perda de conhecimento já citadas pela descrição destas habilidades (know-how) e pelo conhecimento ao cliente (ou unidade cliente) sobre a forma de atendimento, ambos descritos na CSI.

\subsubsection{Provide_Internal_Service isAccessedBy Acess_point}

Uma comunicação oficial entre duas divisões, em que os agentes agem como é descrito na CSI, possui um canal combinando para ocorrer, o ponto de acesso ao serviço. A unidade cliente utiliza o canal de acesso e a unidade fornecedora utiliza o canal de resposta, ambas subclasses do ponto de acesso, que podem ou não ser o mesmo canal.

\subsubsection{Provide_Internal_Service isEvaluatedBy Service_Evaluation}

Ao longo da pesquisa, foram evidenciados os parâmetros considerados importantes pelos entrevistados para avaliar a qualidade de um serviço, conforme apresentado na Figura 18. Esta é outra das principais contribuições deste trabalho, pois pretende-se que, uma vez que as unidades clientes atenderam todos os requisitos solicitados na CSI, a unidade fornecedora provenha o serviço com todos os itens de qualidade: cordialidade, eficiência, eficácia, formalidade e transparência.

\subsubsection{InternalServiceCharter isEvaluatedBy Service_Charter_Evaluation}

Da mesma forma que na seção anterior, a construção de uma CSI deve seguir parâmetros para atender seus objetivos. A Carta de Serviços não pode ser um item meramente ilustrativo, deve ser construída sobre a perspectiva do cliente, do funcionário que busca a informação, e deve resguardar o provedor quanto aos requisitos necessários ao atendimento. A CSI deve ser clara, acessível e utilizar terminologia comum aos entes. Deve ainda permitir buscas e se manter atualizada. O nível de detalhamento só deve ser profundo na descrição do passo-a-passo de como executar o atendimento, para que ocorra GC na unidade provedora.

\subsection{Momento construir III: confecção da wiki piloto}

Como citado anteriormente, a plataforma wiki viabiliza em si 6 das 9 diretrizes para a constituição da CSI, as próximas seções mostram como este potencial foi explorado. Foi criada página com a descrição feita sobre CSI para que os colaboradores entendam seus objetivos e definições. A página inicial da wiki da organização em estudo e na qual o ícone da CSI geral foi inserido para exemplificação, passando a funcionar como ponto focal para a busca por atendimento de serviços.

Para a oferta de cada serviço individual, o modelo ontológico criado na etapa anterior delimita as subclasses de InternalServiceCharterItem: 
justificativa, requisitos, canal, prazo, grau de sigilo, lista-exemplo, normas, categoria negocial, descrição do canal de acesso/resposta e know-how (passo-a-passo da execução do serviço), além da descrição em si.

Para o piloto, foram criadas duas CSI para serviços de um sistema interno denominado SIGA. O sistema tem por objetivo suprir ferramentas e informações para a reversão de crédito e oferece os serviços de suporte técnico e de pedidos de alteração/sugestão, que visam manter sua consistência e aumentar continuamente seu nível de utilidade.

Complementarmente, a oferta de serviço deve funcionar como um catálogo (NARDI et al., 2015), em duas dimensões: catálogo da unidade responsável pelos serviços (unidade fornecedora) e catálogo por assunto. A chave que possibilitou esta ligação foi a classe "categoria negocial" (), com mesmo valor do atributo "categoria" (Internal Service Category, *o) da plataforma wiki. O serviço "SIGA-Suporte técnico" foi incluído nas categorias: sistemas, créditos, ativos, cartilhas, cartas de serviço interna, carta de serviços GESTO (unidade fornecedora do serviço) e carta de serviços SUREC (superintendência nacional imediatamente superior a GESTO).

Ao acessar a página da GESTO na wiki, foi adicionada o link para a categoria "Carta de serviços da GESTO", de forma que, ao clicar acessar a unidade, os usuários têm acesso a sua carta de serviço e seus dois serviços piloto descritos: "SIGA-suporte técnico" e "SIGA-sugestões". Na segunda concepção de catálogo, ao pesquisar termos como "Carta de serviços", "Ativos" ou "Crédito", as duas CSI criadas também são listadas em categorias. A pesquisa simples também permite a busca por palavras no conteúdo das Cartas de Serviço Internas, mas sem uma relação estrutural.

\subsection{Momento habitar: execução do piloto}

O resultado do primeiro item ("Com que frequência você utiliza a wiki da CAIXA (wiki.caixa)?") foi que 22,8\% dos 5.120 participantes acessam a wiki ao menos uma vez por semana. Enquanto que 35,6\% jamais a acessaram. Apesar de se constituir retrato de um momento restrito do tempo, é possível observar uma abertura existente a tal tipo de plataforma na organização e um potencial de crescimento, já que 13,2\% acessam ao menos uma vez por mês. A Figura 8 exibe o resultado geral obtido nesta questão.

Figura 8 - Resultado enquete questão "1", utilização da wiki corporativa 


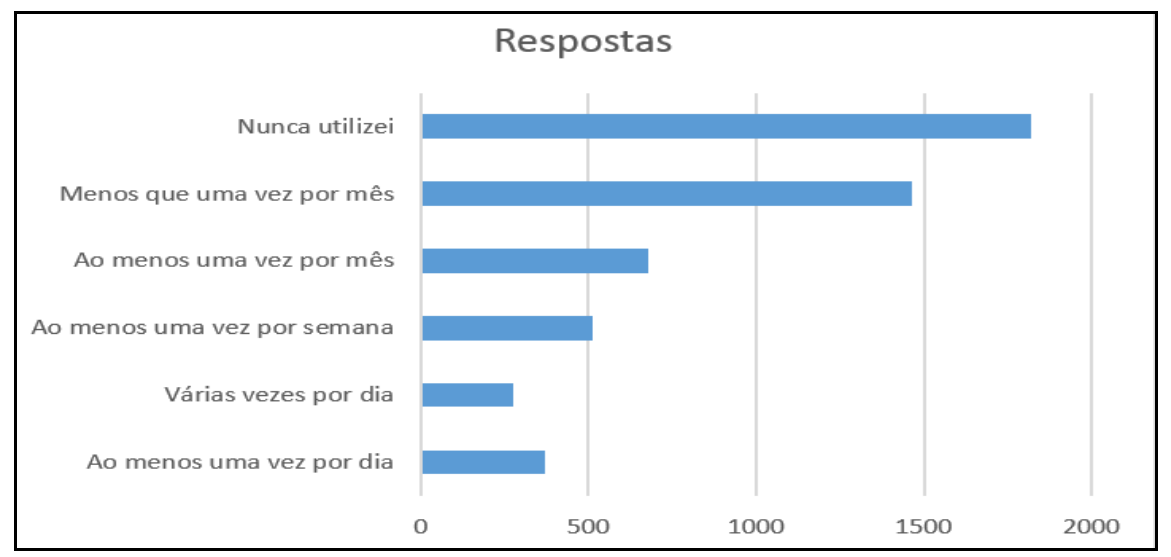

Fonte: Dados da pesquisa.

$\mathrm{Na}$ segunda questão ("Você considera que as duas páginas da wiki.caixa abaixo descrevem adequadamente os serviços de suporte técnico e sugestões ao SIGA?"), 60,2\% dos entrevistados não soubera avaliar se a CSI dos dois serviços estava adequada. Analisando o banco de dados do sistema, observou-se que $15 \%$ destes usuários jamais haviam solicitado os serviços em questão, o que corrobora que cada CSI possui uma comunidade de clientes-alvo em especial. Ignorando essa classe, $81,6 \%$ dos entrevistados concordam totalmente ou concordam parcialmente que as CSI piloto descrevem os serviços a que se propõem.

A terceira questão ("Você considera que o catálogo informado no link abaixo -formado, a princípio, pelos serviços SIGA - suporte técnico e SIGA - sugestões - poderia ser expandido para os demais processos da CAIXA?), exibida na Figura 28, teve um comportamento diferente da segunda. $\mathrm{Na}$ anterior, julgou-se que parte dos usuários não entendiam o serviço e, portanto, não o puderam avaliar adequadamente. Contudo, o item atual questionou sobre a catalogação dos serviços, conceito comum a todas as comunidades de cliente. Desta vez, apenas $46,0 \%$ dos entrevistados não souberam responder e $49,6 \%$ (subindo para $91,9 \%$ ao desconsiderar a classe " 3 ") dos entrevistados concordam com o potencial do catálogo proposto.

Estas três questões tendem a subsidiar o modelo ontológico proposto, pois os resultados se mostraram favoráveis aos conceitos-chave do mesmo, ainda que possíveis acertos devam ser realizados. Neste aspecto, novamente a wiki, através de seus grupos de discussão, presentes em cada página, poderá contribuir. Existe na organização uma unidade de Gestão do Conhecimento responsável por monitorar e moderar as atividades neste ambiente que poderia atuar construtivamente melhorando o modelo inicial, executando novos ciclos na metodologia MAIA.

Caso o modelo venha a substituir na organização estudada a pesquisa generalizada pelo tipo de informação e conhecimento", que constituiu $51,4 \%$ da análise realizada,por uma catalogação eficiente e "viva", poderiam ser mitigados significativamente os custos e prejuízos 
causados neste processo, como os citados por Basili et al. (2001) e Gordon e Lowe (2002).

Adicionalmente, apresentou-se o modelo ao Gerente Nacional em exercício de uma das unidades da recuperação de crédito e foi solicitado a ele que descrevesse as atividades de sua unidade na wiki corporativa. Simultaneamente, ele deveria realizar críticas e sugestões ao modelo, bem como relatar sua experiência. Foi relatado que a forma de registro é simples e funcional, aderente às necessidades da unidade (que já buscava algo parecido).

\section{Considerações finais}

O objetivo principal deste trabalho foi modelar os principais conceitos e relações no contexto dos serviços internos de um banco público brasileiro, por meio de uma ontologia de domínio, para contribuir com a melhora da qualidade da prestação de serviços internos e, em consequência, para o cidadão. A avaliação realizada, tanto teórica quanto prática, indicou que o modelo tem potencial para isto.

Em razão de a organização estudada se tratar de um ente típico da administração pública indireta brasileira e o domínio estudado refletir relações internas que ocorrem em praticamente qualquer instituição, espera-se que a ontologia proposta seja adequada ou, ao menos, sirva como base para outros estudos na administração pública como um todo, contribuindo para a melhoria dos serviços ao cidadão, com a legalidade, a impessoalidade, a moralidade e a publicidade.

A aplicação wiki piloto teve boa avaliação por um grande grupo de entrevistados e foi alterada positivamente cinco vezes após sua criação, o que denota o potencial de capilaridade e interatividade proposto pelo modelo. Entretanto, ainda é importante incentivar o uso da plataforma como uma atividade rotineira dento da organização.

Como contribuição para a Gestão do Conhecimento, ao integrar um formato padrão para retenção de conhecimento para vários tipos de atividades em uma plataforma que já faz parte da cultura organizacional, espera-se que possa ser mitigada a barreira da GC como apenas mais uma atividade. Ao entender os processos como possíveis serviços, reduzse a complexidade do registro dos mesmos e se atinge uma linguagem mais clara e objetiva, para facilitar o compartilhamento do conhecimento.

A ontologia criada (OntoCSI) carrega o conhecimento sobre os conceitos e sobre o contexto utilizados, e pode ser reavaliada em outros contextos para utilização futura. Porter sido concebida no contexto da administração pública indireta, onde parte dos processos organizacionais não se encaixam na lógica de serviços convencionais, o processo de construção da ontologia focou apenas nos processos que envolvem solicitações entre unidades ou departamentos, o que aliás é considerada uma lacuna importante nesse tipo de estudo por vários autores. É preciso também destacar que, embora úteis, as informações advindas das wikis tendem a ser difusas e desestruturadas. 
Consideramos que o modelo de conhecimento construído constitui a principal contribuição deste trabalho. Como sugestões de trabalhos futuros estão a aplicação da pesquisa em outras organizações para validar ou aprimorar a ontologia e a avaliação do tempo médio de execução de determinado grupo de serviços, antes e depois da implantação de suas CSI para medir o impacto de sua utilização.

\section{Referências}

AL-ALAWI, A. I.; AL-MARZOOQI, N. Y.; MOHAMMED, Y. F. Organizational culture and knowledge sharing: critical success factors. Journal of knowledge management, [S.I], v. 11, n. 2, p. 22-42, 2007.

ALMAHAMID, S.; MCADAMS, A. C. The Relationships among organizational knowledge sharing practices, employees' learning commitments, employees' adaptability, and employees' job satisfaction: an empirical investigation of the listed manufacturing companies in Jordan. Interdisciplinary Journal of Information, Knowledge and Management, [S.I], v. 5, p. 327-356, 2010.

ALMEIDA, M, B.; BAX, M, P. Uma visão geral sobre ontologias: pesquisa sobre definições, tipos, aplicações, métodos de avaliação e de construção. Ciência da Informação, Brasília, v. 32, n. 3, p. 7-20, 2003.

ANDRADE, I. A. de et al. Inteligência coletiva e ferramentas web 2.0: a busca da gestão da informação e do conhecimento em organizações. Perspectivas em Gestão \& Conhecimento, [S.I], v. 1, p. 27-43, 2011.

BASILI, V. et al. Um sistema de gerenciamento de experiência para uma organização de pesquisa de engenharia de software. In: NASA SOFTWARE WORKSHOP DE ENGENHARIA, 26, 2001. Anais... NASA Goddard Anual, IEEE, 2001. p. 29-35.

BATISTA, F. F. Modelo de gestão do conhecimento para a administração pública brasileira: como implementar a gestão do conhecimento para produzir resultados em benefício do cidadão. Brasília: IPEA, 2012.

BATISTA, F. F. Gestão do conhecimento na administração pública: o que mudou no período 2004-2014. Brasília: IPEA, 2014.

BEIRA, S. de C. P. Ontologia como um artefato da arquitetura da informação para a representação do conhecimento. 2015. 73f. Dissertação (Mestrado em Gestão do Conhecimento da Tecnologia da Informação) Universidade Católica, Brasília, 2015.

BRASIL. Ministério do Planejamento, Orçamento e Gestão. Carta de Serviços ao Cidadão. SEGES: Brasília, 2008.

BRASIL. Presidência da República. Lei no 6.932, de 11 de agosto de 2009. Dispõe sobre a simplificação do atendimento público prestado ao cidadão, ratifica a dispensa do reconhecimento de firma em documentos produzidos no Brasil, institui a "Carta de Serviços ao Cidadão" e dá outras 
providências. Diário Oficial [da República Federativa do Brasil], Brasília, DF, 23 ago. 2009.

BROOKING, A. Corporate memory: Strategies for knowledge management. Londres: International Thomson Business Press, 1999.

CAMPI, M. E. Análise de qualidade e desempenho em relação a processos internos: o caso do departamento de materiais indiretos do setor de suprimentos de uma empresa de tecnologia avançada. 2012. 122f. Dissertação (Mestrado profissional em Administração) - Faculdade de gestão e negócios, Universidade Metodista de Piracicaba, Piracicaba, 2012.

COSTA, I. de M. Um método para arquitetura da informação: fenomenologia como base para o desenvolvimento de arquiteturas da informação aplicadas. 2009. 149f. Dissertação (Mestrado em Ciência da informação) - Faculdade de Ciência da Informação, Universidade de Brasília, Brasília, Dez. 2009. Disponível em: <http://repositorio.unb.br/handle/10482/7087>. Acesso em: 19 Jun. 2014.

COUTINHO, R. L. F. Instrumentos de participação cidadã na câmara dos deputados. E-Legis-Revista Eletrônica do Programa de Pós-Graduação da Câmara dos Deputados, [S.I], v. 13, n. 13, p. 21-42, 2014.

DAGHFOUS, A.; BELKHODJA, O.; ANGELL, L. C. Understanding and managing knowledge loss. Journal of Knowledge Management, v. 17, n. 5, p. 639-660, 2013.

EIRIZ, V.; SIMÕES, J.; GONÇALVES, M. Obstáculos à gestão do conhecimento nas escolas de gestão e economia do ensino superior público em Portugal. Comportamento organizacional e gestão, [S.I], v. 13, n. 2, p. 153-167, 2007.

FOX, M. S.; BARBUCEANU, M.; GRUNNINGER, M.; LIN, J. An organization ontology for enterprise modelling. Menlo Park CA: AAAI, 1997.

GIANESI, I; CORRÊA, H. L. Administração estratégica de serviços: operações para a satisfação do cliente. São Paulo: Atlas, 1996.

GORDON, J; LOWE, B. Employee retention: approaches for achieving performance objectives. Journal of American Academy of Business, Cambridge: v. 1, n. 2, p. 201-205, Mar. 2002.

GUIZZARDI G.; FALBO, R. A.; GUIZZARDI, R. S. S. Grounding software domain ontologies in the Unified Foundational Ontology (UFO): the case of the ODE software process ontology. In: IBEROAMERICAN WORKSHOP ON REQUIREMENTS ENGINEERING AND SOFTWARE ENVIRONMENTS, 11., Espírito Santo, 2008. Proceedings... Vitória: Universidade Federal do Espírito Santo, 2008. p. 244-251.

HOEHNDORF, R. et al. BOWiki: Um wiki baseado em ontologias para anotação dos dados e integração de conhecimentos em biologia. BMC Bioinformatics, Leipzig, Alemanha, v. 10, n. 5, 2009. Disponível em: 
<https://doi.org/10.1186/1471-2105-10-S5-S5>. Acesso em: 13 abr. 2018.

KAPLAN, R. S.; NORTON, D. P. The strategy-focused organization. Boston: Harvard Business School Press, 2001.

LOPES, A.; NÓBREGA, I.; PACHECO, K. Um guia de serviços do Governo Federal baseado em ontologias. 2014. 34f. Trabalho de Conclusão de Curso (Bacharelado em Sistemas de Informação) - Universidade Católica de Brasília, Brasília, 2014.

MADSEN, T. L.; MOSAKOWSKI, E.; ZAHEER, S. The dynamics of knowledge flows: human capital mobility, knowledge retention and change. Journal of Knowledge Management, [S.I], v. 6, n. 2, p. 164-176, 2002.

MANDAJI, M. O processo de colaboração nos trabalhos de coautoria em ambientes virtuais de aprendizagem. Revista Brasileira de Informática na Educação, [S.I], v. 20, n. 1, p. 50, 2012.

MENDONCA, F. M.; CARDOSO, A. M. P.; DRUMOND, E. Ontologia de aplicação no domínio de mortalidade: uma ferramenta de apoio para o preenchimento da declaração de óbitos. Ciência da Informação, Brasília, v. 39, n. 3, p. 23-34, dez. 2010.

MORESI, E. A. D.; RAMOS, R. G. C.; PRADO, H. A. do. Mapeamento de informações organizacionais: um estudo na Embrapa. Transinformação, [S.I], v. 22, n. 2, p. 101-110, 2010.

NARDI, J. C. et al. A commitment-based reference ontology for services. Information Systems, [S.I], v. 54, p. 263-288, 2015.

NOY, N. F.; MCGUINNESS, D. L. Ontology development 101: a guide to creating your first ontology. [S.I: s.n.], 2000. Disponível em: $<$ http://citeseerx.ist.psu.edu/viewdoc/download?doi=10.1.1.136.5085\&re $p=$ rep1\&type $=p d f>$. Acesso em: 23 jan.2015.

PERROTT, B. E. A strategic risk approach to knowledge management. Business Horizons, [S.I], v. 50 n. 6, p. 523-533, 2007.

SÉRGIO, M. C.; DA SILVA, T. do N.; GONÇALVES, A. L. Representação do domínio de conhecimento acadêmico e uma teoria de representação: a ontologia de fundamentação unificada. International Journal of Knowledge Engineering and Management (IJKEM), [S.I], v. 5, n. 11, p. 51-69, 2016.

SIQUEIRA, A. H. Arquitetura da informação: uma proposta para fundamentação e caracterização da disciplina científica. 2012. 444f. Tese (Doutorado em Ciência da Informação) - Faculdade de Ciência da Informação, Universidade de Brasília, Brasília, Ago. 2012.

SLACK, N.; CHAMBERS, S.; JOHNSTON, R. Administração da produção. 2. ed. São Paulo: Atlas, 2009.

STACHEIRA, C. R. Intersetorialidade em políticas públicas de enfrentamento à violência contra a criança e o adolescente: proposta de 
Formalização de serviços internos em grandes corporações: Proposta de ontologia para construção colaborativa de Carta de Serviços

um modelo de formalização do conhecimento na forma de ontologia. 2014. 136f. Dissertação (Mestrado profissional em Gestão do Conhecimento e Tecnologia da Informação) - Universidade Católica de Brasília, Brasília, 2014.
Maurício Telles Bígio; Remis Balaniuk; Ana Paula Bernardi da Silva; Vitória Santiago da Silveira 